\title{
Rhizolith Island Prototyping a Resilient Coastal Infrastructure
}

JULIE LARSEN

Syracuse University

Rhizolith Island is a proof of concept design project that investigates floating, high performance concrete structures as a new, resilient coastal infrastructure that revitalizes depleting mangrove forests along vulnerable shorelines with continual flooding. The project is a collaboration between the authors, CEMEX Global R\&D in Biel, Switzerland, JJSmithGroup Coastal Engineering, governmental agencies of Cartagena, Colombia, and local NGOs. The project uses new high performance and lightweight concrete technology to strengthen ecological performance of coastal infrastructure and reinforces appreciation for the ecologies that surround and protect communities. As a new, protective infrastructural type, the island is a resilient barrier that protects and enables new mangroves to grow and thrive while creating a public edge for visitors to engage with along the shore.

\section{INTRODUCTION}

Due to the devastating depletion of mangrove forests that naturally control sediment and shorelines from erosion, the project aims to repopulate mangrove forests along vulnerable shorelines in Cartagena, Colombia. A first prototype for Rhizolith Island was supported by the Cartagena Port Authority and the Naval Academy of Cartagena and was exhibited in the context of a concrete expo, 'RC 2016 Reunion del Concreto', in the old harbor of Cartagena, Colombia (Fig. 1). Based on the success of this prototype, the National Park Los Corales del Rosario and San Bernardo and the Cartagena Port Authority decided to support the further development of the Rhizolith Island as a proof of concept project to be implemented on Isla Grande off the coast of Cartagena. The city is interested in the project because they are looking for new ways to combat mangrove loss and subsequent flooding with soft and resilient infrastructural approaches that go beyond typical single purpose shoreline protection. Their interest is in providing solutions that respond to different site conditions while maintaining an aesthetically enriching public shoreline.

Mangroves, typically are highly productive forests built by a small group of trees and shrubs that have adapted to survive in the harsh interface between land and sea; often in places where rainforests meet oceans ${ }^{1}$. Mangroves play a crucial role in reducing vulnerability to natural hazards and increasing resilience to climate change, by acting as a form of natural coastal defense. Mangrove forests work as a defense mechanism because they play a central role in transferring organic matter and energy from the land to marine

\section{ROGER HUBELI}

Syracuse University

ecosystems. This matter and energy comes from detritus from fallen leaves and branches, and forms the base of important marine food chains ${ }^{2}$. However, mangroves are disappearing three to five times faster than overall global forest losses ${ }^{3}$. Human pressure on coastal ecosystems is often high, with land competition for aquaculture, agriculture, infrastructure and tourism. The conversion of mangrove areas to other uses over the past decades has been alarming with around some 15.2 million hectares of mangroves estimated to exist worldwide as of 2005, down from 18.8 million hectares in $1980^{4}$.

And although mangroves have the capability to 'keep up' with some sea level rise through accumulation of sediment and organic matter in the soil, any effort to grow further back from the sea is thwarted by urbanization ${ }^{5}$. So, mangrove forests are literally being pinched in both directions from rising sea levels on one side and agriculture and hard urban edges on the other. Due to this setback of growth, Rhizolith Islands aims to repopulate mangrove forests along vulnerable shorelines with aggregated, prefabricated concrete elements. The design of the Rhizolith Island is following the argument that "nature increasingly appears as a fragile entity that is itself in need of infrastructural support", ${ }^{6}$ serving as a response to the threats to the Colombian coastal region and providing the necessary infrastructural support to improve the shorelines and mangrove population.

\section{BACKGROUND}

As climate change becomes the norm, heavy storm surges and flooding require cities to take a different approach to nature. Continual urban growth, agriculture, and storm surges, in many countries around the world, contribute to devastating amounts of vegetation and habitat loss. And when "clearing mangroves" for new urban developments, this also "endangers humans because mangroves protect and stabilize coastal areas, and when they are removed, tidal waves can do greater damage." ${ }^{\prime 7}$ Continual storm surges accelerate the depletion of mangroves along shorelines, which in turn makes urban areas even more vulnerable to flooding. In an effort to reverse this development, the project aims to achieve a soft, urban infrastructure that provides a floating protective barrier for new mangroves and marine life to grow and thrive in areas where more normative restoration does not work. This floating barrier is only achieved with a new composite of high strength and lightweight concrete mixes, to help redefine ecological performance for new coastal infrastructure. 


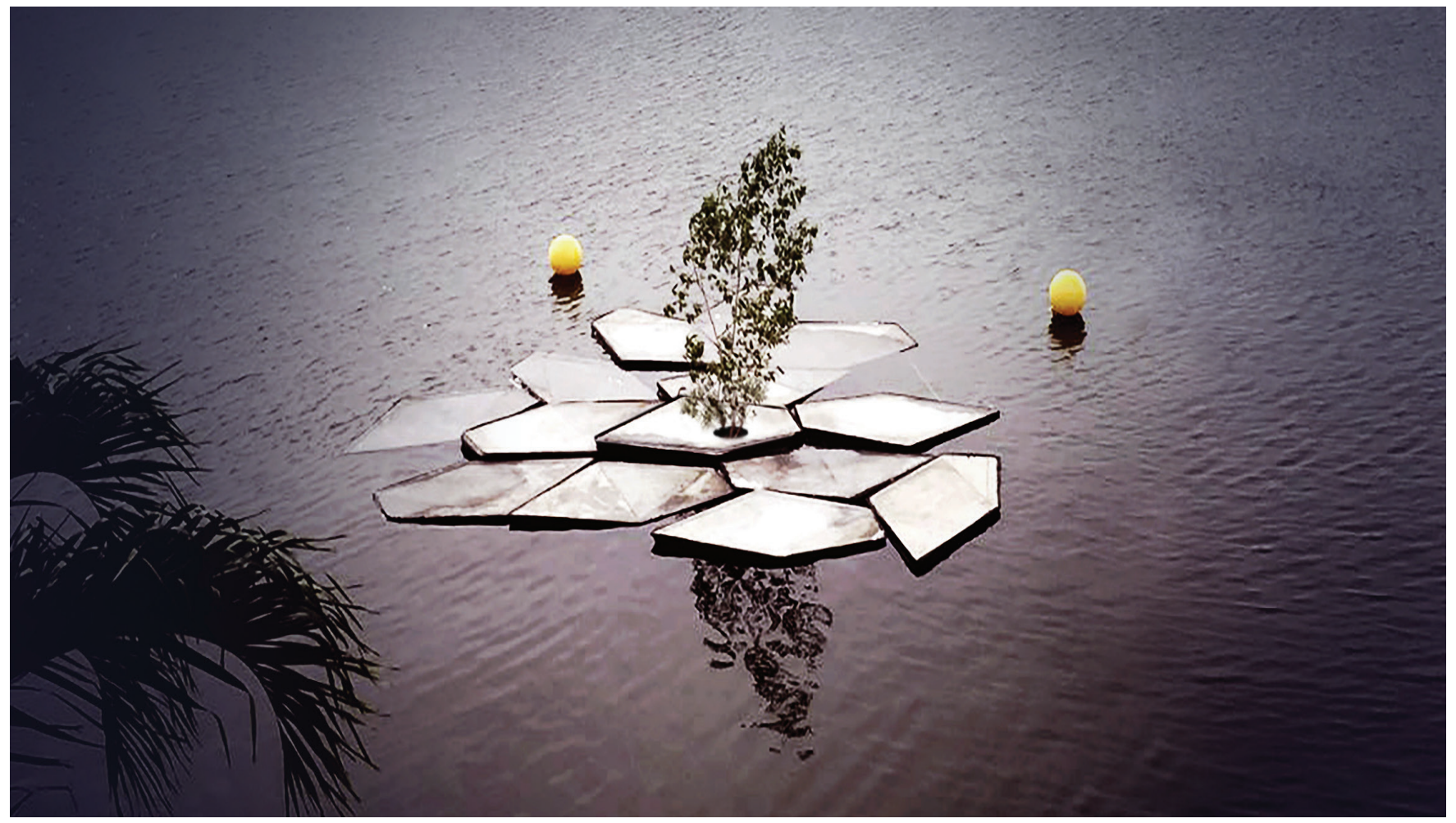

Figure 1: Rhizolith Island first prototype, exhibited in Cartagena, Colombia (Source: Author)

The Naval Academy has investigated ways to combat inevitable annual storm surges and floods with breakwater armor systems, such as Xblocs and Tetrapod structures, most of which create a permanent, hard-infrastructural barrier between water and land. The city, however, would like to avoid hard breakwater applications due to their inability to be responsive to different site conditions, typically serving a singular use, and aesthetically diminishing the quality of the shoreline; all issues to overcome in many tourist destinations. Therefore, as a floating breakwater, rather than a hard edge, Rhizolith aims to create a resilient, soft infrastructure with three goals: protect and grow new mangroves, create well-crafted objects that ecologically perform, and design elements that can aggregate into different configurations to work in many different site conditions. To achieve this, the island is conceived as infrastructural elements through materiality and form, following D'Hooghe's argument that "any design of a contemporary infrastructure object should begin and end with an acknowledgement of the object crafted," ${ }^{\prime 8}$. Unlike typical applications of infrastructure where the "material presence...is subservient to its bigger purpose," the project flipped the approach to rethink the performance and form of the breakwater elements to address protection of mangroves in high waters but to also address the public quality of the design. A key component to making the project viable for the City of Cartagena was to not only engineer a solution for littoral environments but design the forms to ensure high quality public and recreational spaces that people can engage with along the shoreline.

\section{PRECEDENTS}

The precedents for the project range from conceptual and formal references, to very specific applications of living shorelines and breakwaters in coastal regions. Existing floating ecological systems of naturally forming pumice islands, similar in material quality to porous concrete, are found in the vicinity of volcanic activity close to shorelines. Such is the case as the floating islands inhabited by the Uru People on lake Titicaca in Peru and Bolivia. Other types of precedents are Mangrove reforestation efforts such as the Mangrove Action Project which provides a holistic approach to mangrove reforestation by including research, education, community engagement and outreach ${ }^{10}$. But many of the current mangrove reforestation efforts focus more on reforesting natural environments with new mangroves without the challenge of working in littoral environments, relatively deep waters with strong waves, and don't need to mitigate between nature and the urban environment. The following precedents were instrumental to the development of the project.

Living Shoreline Breakwaters - There are many living breakwater strategies that served as a catalyst for Rhizolith Island; many of which stem from the Rebuild by Design 
competition. No longer are we seeing levee walls as a desirable solution because of its hard edge as well as its lack of any spatial quality and thoughtfulness to the public aspects of waterfronts in urbanized areas. Kate Orff's Living Breakwater, a project conceived for the Rebuild by Design competition, looks at how to embed new habitats within a soft breakwater and still provide public access. ${ }^{11}$ To keep water out and reduce flooding, most design strategies, like Orff's, use marshlands, beaches, wetlands and mangroves. There are a number of variables that must work in order to contribute to the success of a living shoreline. Limitations include "wave climate, regulatory policies, and property ownership". ${ }^{12}$ And in order to "create an enduring living shoreline, the wave environment it is exposed to must generally stay below three feet (one meter) in height, a threesecond wave period and blows less than a three mile stretch of open water."13 These projects were closer in conception to the goals of the project but elements were never used in deep water conditions that had to simultaneously grow mangroves while protecting the shoreline. The Buras Boat Harbor by JJSmith Group Coastal Engineering uses a series of elements to create a living breakwater condition along the shoreline. The 'On the Water | Palisade Bay' coastal research project, by Guy Nordenson, Catherine Seavitt Studio and ARO, deals with similar oceanic forces acting on a soft infrastructure in the New York-New Jersey upper bay. Both projects look at wave and erosion patterns to design and situate soft edged infrastructural elements that help mitigate floods and allow for the reestablishment of marine habitat. These projects were highly influential in their coastal approach to the project and the amount of surface area needed to protect the shoreline but were not designed to grow mangroves, only marine vegetation.

Mangrove Restoration Solution - The Reef Ball Mangrove Solutions Organization deploys mangrove restoration strategies but typically in non-urbanized sites and in much shallower waters. The organization combines their 'reef ball' technology with split encasement tubes to stabilize the seedlings and ensure the fastest, healthiest, and most protected growth of the mangrove tree. ${ }^{14}$ While this precedent helped in the design and development of the conceptual framework of Rhizolith Island, more specific engineering projects will be used to develop more detailed and technical modeling to design a resilient coastal strategy that provides an adequate ecosystem for natural habitats and mangroves to return while still withstanding heavy storms and sedimentation that isn't rich in nutrients for mangroves.

\section{DESIGN STRATEGY: FOR VERSUS AGAINST NATURE}

Before the environmental crisis, "nature served as the support for infrastructure", such as the Hoover Dam or Niagara Falls, "exploited the productive power of nature to the benefit of mankind." ${ }^{15}$ Coastal infrastructural strategies, such as levee walls and fixed wave breakers, are 'single-purpose' systems,


Figure 2: Three phases of Rhizolith Island, 1. planting mangroves, 2. Growing mangroves to maturity and 3. Concrete breaks and mangroves return as the dominant flood protection mechanism (Source: Author).

also meant to benefit mankind, and are traditionally used in threatened, urbanized areas prone to flooding. These systems are less resilient because they are short-term strategies that are known to increase long-term flood risk. They are built to protect a particular area but are designed as barriers to resist water and overcome nature as an obstacle. But as extreme climatic change becomes the norm, design of coastal infrastructure must flip and support nature, rather than exploit or resist it, which compounds the original problems.

The conceptual design strategy of the island stems from a provocation by Lebbeus Woods, after the 2012 Tsunami, on the role of design in catastrophic events, "Can architects somehow design for earthquakes and tsunami, or only against them?"16 In response to this question, if we aim for the latter - against - we must assume that in order to be against something, we must be in opposition to it or resistant to its effects. This sets up a clear boundary between what needs to be 'protected' (vulnerable forest, ecosystems, urban development) and what those bodies need to be protected from (recurring natural disasters, sea level rise). But if we assume the former - for there is a potential for reciprocity between systems, rather than exploitation of one over the other.

New infrastructural boundaries along cities require a different perspective to nature - solutions that work for nature, rather than against it. Infrastructure that is not a 




Figure 3: Aggregation of elements into larger field condition (Source: Author)

linear, single purpose protection measure, such as dams and seawalls but a breakwater that becomes a field condition, creates more varied interaction with the environment and more opportunities for visitors. Following Lebbeus Woods' suggestion to "design for rather than against nature," Rhizolith Island is the design of a soft, resilient breakwater made with floating concrete elements that work 'for' nature by floating above the water; enough to break waves, without having to resist them to protect the shoreline. Especially since mangrove forests are the "ultimate illustration of why humans need nature with their ability to prevent erosion and mitigate natural hazards, a natural coastal defense whose importance will only grow as sea level rise becomes a reality around the world." ${ }^{17}$ As a temporal structure, the design strategy recognizes that man-made structures cannot provide as resilient or as ecologically complex of flood protection as mangroves. Similar to mangroves with "above-ground roots that slow down water flows, encourage deposition of sediments and reduce erosion,"18 the proposal aims to achieve floating elements that temporarily and artificially mimic the above-ground roots of the mangroves to provide a protective barrier for water to slowly pass under and around the elements. The design of the elements then provide protection for the roots of the mangroves to grow and allow nature to envelope and take over the structure over time as the preferred flood prevention (Fig. 2).

\section{PILOT PROJECT}

The team's pilot site for the proof of concept will be the Laguna Encantada in Isla Grande, off the shore of Cartagena. The edge of the lagoon has always been heavily forested with mangroves that bleeds into the Caribbean Sea. The lack of mangroves to protect the lagoon has greatly diminished the quality of marine life, the natural ecosystem, and mangroves surrounding the lagoon. As is the case with the mangroves abutting the lagoon, many "mangroves are particularly threatened in tropical coastal areas...the breeding grounds for many species of fish that grew up among the mangrove roots [are] destroyed"19 as seen in 2016 when Isla Grande lost many mangroves buffering the lagoon and leaving two unprotected gaps to the lagoon that continue to threaten the ecosystem.

Without a floating, protective surface to keep mangroves above water, the coastal site of Isla Grande, with its exposure to the open sea, would otherwise be too challenging for mangroves to survive everyday wave occurrence, let alone harsh storm surges, as they grow. And due to the island being frequented by tourists, the Colombian Naval Academy is interested in providing a soft infrastructure strategy that not only protects the lagoon and provides shelter for mangroves, but also becomes a water feature for tourists and an opportunity to create awareness for visitors of the unique ecosystem they are inhabiting and enjoying. The project goals are to rejuvenate lost mangroves and design the concrete elements to intentionally break so the site reverts back to a more 'natural' state where mangroves, once again, control flooding. At the pilot site the intent is to test the elements at a larger scale to protect approximately 50 meters of coastline.

\section{DESIGN STRATEGY}

To derive a formal, material and performative logic through the use of concrete, the project began with the concept of 'Rhizolith'. According to the British Encyclopedia, 'rhizolith' derives from "fossilized root systems that were once encased in mineral matter and formed through a process of chemical weathering and cementation". ${ }^{20}$ Rhizolith Island 


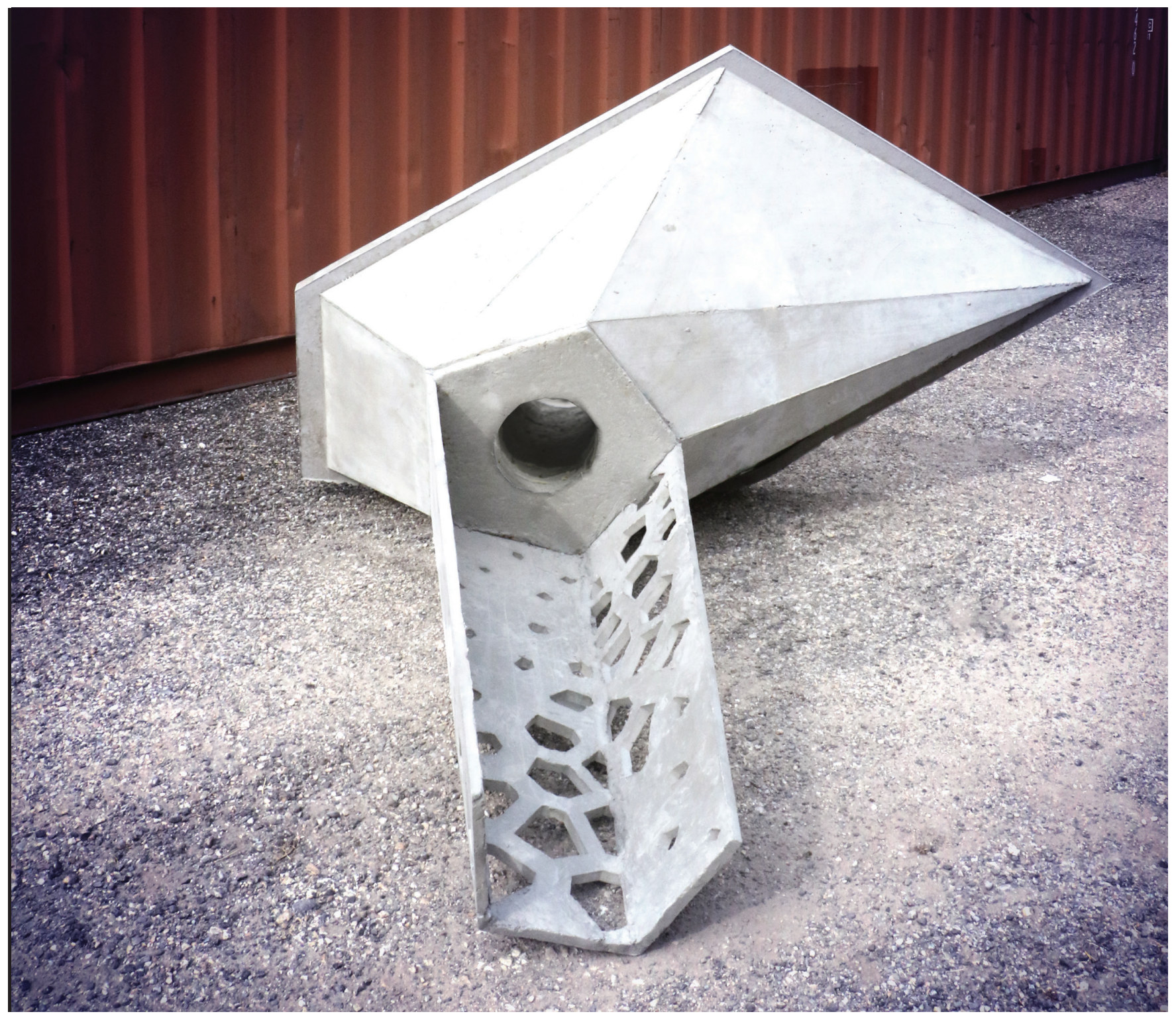

Figure 4: Single Rhizolith Island element, 10-20 of these elements make up one island (Source: Author).

is conceptually aimed to begin as an artificial rhizolith that slowly returns to a natural, fossilized form of rhizolith over time. The design of the breakwater prototype, as an 'artificial root system,' is comprised of 'root-like' concrete modules that work like an artificial rhizolith. It begins as a completely artificial, concrete structure but eventually 'fossilizes' and is taken over by the mangroves; thus, bringing the 'rhizolith' back to a natural state.

The approach of Rhizolith Island is that the structures float above water to protect mangrove seedlings in littoral environments with much more water depth and waves than in typical reforestation projects commonly located in shallower water. The islands create a floating protective breakwater that always remains above water in order for new mangroves to grow, responding to rising sea levels and ensuring mangrove seedlings stay above water while roots grow naturally down to the seabed. This is critical because without a way to keep mangroves above water, the site would be too challenging for mangroves to survive changing sea levels, harsh storm surges, or recurring waves, as they grow. For the islands to be effective as a resilient breakwater, in deeper littoral environments with rising sea level change and high waves, the design approach as a coastal infrastructure is to be a field condition of floating elements hovering over the water, which means the overall field absorbs and moves with the water, rather than creating a hard edge that resists it (Fig. 3).

The island modules work as protective barriers for planted mangrove seedlings to grow in harsh storm surges and waves that would otherwise wash them away if not protected. The concrete modules are made with a specific designed 


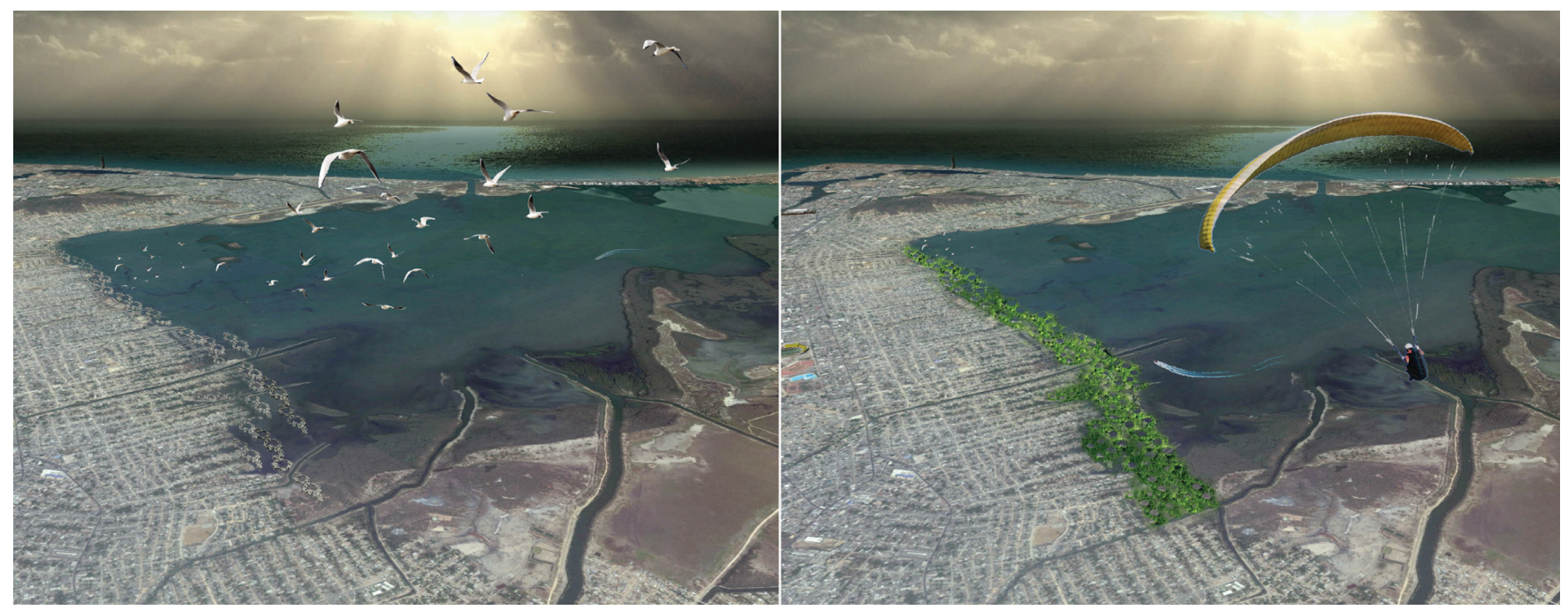

Figure 5: Rhizolith Island Urban Speculation, shoreline of Cartagena, Colombia (Source: Author).

combination of concrete mixes to encase planted mangroves, while concrete fins below water create new habitats. The individual concrete modules aggregate into island clusters that can then aggregate into even larger, buoyant fields that act as a soft breakwater. The field aggregations also have the potential to become a larger, public infrastructure for urban growth. When the islands aggregate to a field, variation in the pattern creates gaps for boats and kayaks to pass through the islands, as well as for marine enthusiasts to enjoy the living breakwater as a place for recreation; added value to the growth of the urban spaces the breakwater intends to protect. Over time, the concrete elements survive long enough to protect the mangroves as they mature but are designed to fail so mangrove roots can easily moor into the seabed. As the roots break the elements, they sink to the seabed. Since concrete is rich in calcium, due to the limestone content of the cement, the elements will also help to support the growth of coral reefs that adjoin the lagoon.

\section{FABRICATION}

To ensure that the individual concrete elements are able to float and remain stable, they are made with a specific designed combination of high strength concrete technologies on the exterior of the element and lightweight and porous concrete on the inside of the element to create buoyancy as well as encase planted mangrove seedlings. The concrete fins, attached to underside of the structure, sit below water to create new habitats for local ecologies to develop around the elements as mangrove roots grow and moor into the seabed.

The individual elements of the breakwater are constructed of two individual pieces; a head and a fin, made with two different proprietary concrete mixes; one for strength, the other for lightness (Fig. 4). The fin of the element is made of high performance concrete that is needed for it to be strong and moor into the seabed over time and stabilize the structure. It formally has lightness due to the many voids in the surface of the fin to encourage flora, fauna, debris, and leaf litter to entangle itself into the structure. It's weight and strength stabilizes the elements in the water and provides a basis for the development of a marine habitat. The head of the element is made from a concrete mixture that is lighter than water and guarantees the island floats even if there are holes in the shell. In comparison to typical concrete, the concrete modules are half the weight so they can more easily be assembled off-site, shipped and placed into position. In the center of the element, a hole is created and filled with a porous concrete cylinder that encases the mangrove seedling.

Rhizolith Island is comprised to float, but more importantly, the lightweight and porous concrete is a weaker mixture that permits the roots of the mangroves to break the concrete and grow through it - leading to the eventual 'failure' of the concrete. Over time, the concrete elements survive long enough to protect the mangroves as they mature but are designed to fail, break, and sink so mangrove roots can easily grow and moor into the seabed. By the time the concrete fails and breaks, it is already trapped in the roots of the mangrove and other naturally formed debris and leaf litter that will accumulate within the shell of the fin and head of the module. The timing of the concrete elements breaking for the mangroves to take over is a new approach to the design of soft infrastructure because concrete rarely wants to intentionally fail. But in this case, CEMEX Global R\&D is designing the mix in relationship to the force of the mangrove roots to have enough strength to protect the mangroves as they become mature but weak enough to break once the mangroves are fully grown. After several years, shorelines are eventually 
revitalized and revert back to a natural flood protection, where mangroves are the dominate flood mitigator (Fig. 5).

\section{PROJECT DEVELOPMENT}

While the first prototype that was exhibited and tested in the harbor of Cartagena was able to prove that the concrete technology and the method of construction can be successfully implemented for this application, currently, testing is being done to study the relationship between the concrete and the growth of the mangroves. According to the coastal engineers, the controllability of the height above water is the next phase of the project to ensure that elements can attenuate waves with approximately .4 - .6 meters raised above water. We are also working with a local NGO to test the rate of growth of individual mangroves in the porous concrete elements that will be part of the individual elements and serve as an incubator for the mangroves.

A series of tests were made of mangroves in the early stage of growth and development in the porous concrete. A local NGO in Cartagena is growing mangroves in concrete elements to test their ability to withstand the unique environment of the concrete with the first results being promising. Next, the elements will be brought to the open waters to see the rate of growth, expansion, and mooring capability of the mangroves in the concrete elements on site. If this is successful, the plan is implementing additional elements to test their ability to grow.

\section{CONCLUSION}

The impact of Rhizolith Islands starts with Isla Grande but the aim of the project is to far exceed the coastline of Colombia. Cities throughout the world are learning to accept that coastal erosion, mangrove depletion, and flooding are due to global warming, industrialization and, urban development. The loss of mangrove forests contributes to increased flooding and loss of valuable habitat. Since catastrophes do not represent decimations or extinctions of many species, but rather provide the crucial impetus for new developments ${ }^{21}$, there is potential for ongoing wave action or storm surges to spur new solutions to protect shorelines. Rhizolith Islands showcases an infrastructural strategy that ensures the longevity, protection, and possibility to include mangrove forest into the urban development of coastal cities while still maintaining a public interface with visitors and locals. To solve the larger issue of mangrove depletion, this will still require that urban development in the future not encroach on coastlines to ensure that mangroves remain the prominent flood mitigator.

Natural occurrences will continue, from storms to mangrove deforestation, but design can inevitability be the impetus for productive change. Rather than designing an infrastructure that is singular in its purpose and resists natural occurrences,
Rhizolith Islands is resilient and multifaceted in its approach and designed for nature. This strategy ensures the longevity needed to protect the natural surroundings of Isla Grande and potentially other sites. There is an opportunity to design for nature and accept that human intervention can play an important role in supporting nature but without the need to control it. To design for failure understands that nature will endure and be the impetus for productive change is already within the natural environment itself.

\section{ENDNOTES}

1. Spalding, Mark D., Mami Kainuma, and Lorna Collins. World atlas of mangroves. London: Earthscan, 2010, 107-109.

2. LeGuen, Roger, "Blue Planet: Mangrove forests," WWF, Accessed July 12, 2017. http://wwf.panda.org/about_our_earth/blue_planet/coasts/ mangroves/.

3. "UNESCO calls for better protection of mangrove ecosystems," United Nations, July 26, 2016. Accessed July 13, 2017, http://www.un.org/ sustainabledevelopment/blog/2016/07/on-first-international-day-unescocalls-for-protection-of-mangrove-ecosystems/.

4. “The world's mangroves 1980-2005 Report 2007," FAO Forestry Paper 153, Food and Agriculture Organization of the United Nations Rome, 2007, 9-13.

5. Spalding, World atlas of mangroves, 107-109.

6. Picon, Antoine. Nature, Infrastructure and Cities, In P. Scott Cohen \& E. Naginski (eds.), The return of nature: sustaining architecture in the face of sustainability, New York: Routledge, 2014, 173.

7. Gleich, Michael, Dirk Maxeiner, Michael Miersch, and Fabian Nicolay, Life counts: cataloguing life on earth, New York: Atlantic Monthly Press, 2002, 150.

8. D'Hooghe, Alexander, "The Objectification of Infrastructure: The Cultura Project of Suburban Infrastructure Design," In Infrastructure as architecture: Designing composite networks, by Katrina Stoll and Scott Lloyd, Berlin: Jovis, 2010, 78

9. ibid.

10. "About Us," Mangrove Action Project, 2013, Accessed July 12, 2017, http:// mangroveactionproject.org/about-us/.

11. Orff, K., Nordenson, G., C. Seavitt Nordenson, Adam Yarinsky, "Living Breakwaters Rebuild By Design Competition," Scape Studio, 2014, Accessed July 12, 2017, http://www.scapestudio.com/projects/ living-breakwaters-competition/.

12. Cox, Jack, "Living Shorelines: A Hard Look at the Softer Future of Marina Design," Marina Dock Age, July 2016, 19

13. ibid

14. "Explore Mangrove Solutions," Mangrove Solutions, accessed July 13, 2017 http://www.mangrovesolutions.com/index.html.

15. Picon, Nature, Infrastructure and Cities, 172.

16. “Lebbeus Woods, "Questioning Catastrophe," Lebbeus Woods Blog, January 23, 2012, accessed August 2013, http://Lebbeuswoods.Wordpress. Com/2012/01/23/Questioning-Catastrophe/.

17. Spalding, World atlas of mangroves, 107-109.

18. Spalding, Mark, Mangroves for coastal defence guidelines for coastal managers \& policy makers, Wageningen: Wetlands Internat., 2014, 22.

19. Gleich, Life counts: cataloguing life on earth, 150

20. “Meaning of Rhizolith," Encyclo.co.uk, accessed February 28, 2017, http:// www.encyclo.co.uk/meaning-of-Rhizolith.

21. Reichholf, J. H.,Progress through Catastrophes: How Extinctions Further Evolution, in Spalding, M. (ed.) Life Counts: Cataloguing Life on Earth, New York: Atlantic Monthly 2002, Press, 133 